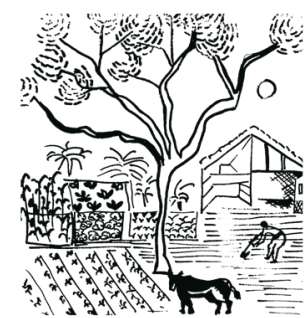

\title{
Perspectivas da cooperação e do desenvolvimento sustentável
}

\author{
Nelson José Thesing ${ }^{1}$ \\ Romualdo Kohler ${ }^{2}$ \\ Luciana Moro de Souza ${ }^{3}$ \\ Tiago Rodrigo Lutzer Tizotte ${ }^{4}$
}

Resumo: O movimento cooperativista conquistou ao longo dos séculos, um espaço socioeconômico, em vários países do mundo, privilegiado por contar com a presença de milhares de associados, qualificou-se como um ambiente laborativo fértil para pesquisas científicas. Assim, o estudo objetiva trazer uma reflexão sobre a oportunidade da cooperação, na dinâmica do desenvolvimento sustentável, em um mundo que se apresenta com alta complexidade, onde as interfaces entre o movimento cooperativista e a sustentabilidade, apresentam a coexistência entre a cooperação e a competição. Essas inquietações trilham o caminho metodológico, alicerçado pela pesquisa bibliográfica, descritiva, interpretativa, de abordagem qualitativa, ao verificar a cooperação em uma cooperativa de crédito. Os achados da pesquisa apontam que o Conselho Fiscal, na cooperativa de crédito, é um órgão que estabelece uma relação de trabalho com o Conselho Administração, oportuniza um ambiente de transparência, das atividades da cooperativa. Esse processo apresenta a adoção de boas práticas de gestão, contribuindo com o desenvolvimento do quadro associativo e da comunidade onde está inserido. Assim, a cooperação passa a ser vista como um mecanismo de prestação de serviços, para além, apresentar um processo de trabalho com poder de gerar uma melhor distribuição de renda, de forma democrática, com objetivos econômicos e sociais comuns, distintos de outras sociedades mercantis, que nem sempre buscam minimizar a escassez de oportunidades econômicas, as privações sociais, obstáculos à liberdade, que de certa forma, credenciam o mundo da cooperação para a conquista de uma sociedade sustentável.

Palavras-Chave: Competição. Cooperação. Sustentabilidade. Complexidade.

\section{THE WORLD OF COOPERATION AND SUSTAINABLE DEVELOPMENT}

Abstract: The cooperative movement has conquered over the centuries, a socioeconomic space, in several countries of the world, privileged for having the presence of thousands of associates, has qualified as a fertile working environment for scientific research. Thus, the study aims to bring a reflection on the opportunity for

\footnotetext{
${ }^{1}$ Professor do Departamento de Ciências Administrativas, Contábeis, Econômicas e da Comunicação da Unijuí. Integra o Corpo Docente do Programa de Pós-Graduação Stricto Sensu, Mestrado e Doutorado em Desenvolvimento. E-mail:nelson. thesing@unijui.edu.br

${ }^{2}$ Professor do Departamento de Ciências Administrativas, Contábeis, Econômicas e da Comunicação. Integra o Corpo Docente do Programa de Pós-Graduação Stricto Sensu, Mestrado e Doutorado em Desenvolvimento e faz parte do Grupo Interdisciplinar de Estudos em Gestão e Políticas Públicas, Desenvolvimento, Comunicação e Cidadania - GPDeC. E-mail: romualdo@unijui.edu.br

${ }^{3}$ Doutoranda em Desenvolvimento Regional pela Universidade Regional do Noroeste do Rio Grande do Sul Unijuí e integrante do Grupo Interdisciplinar de Estudos em Gestão e Políticas Públicas, Desenvolvimento, Comunicação e Cidadania -GPDeC.E-mail: luciana.souza@americalatina.edu.br

${ }^{4}$ Mestrando do Programa de Pós-Graduação Stricto Sensu em Desenvolvimento Regional na Unijuí. E-mail: tiago.tizotte@ hotmail.com
} 
cooperation, in the dynamics of sustainable development, in a world that presents itself with high complexity, where the interfaces between the cooperative movement and sustainability, present the coexistence between cooperation and competition. These concerns follow the methodological path, based on bibliographic, descriptive, interpretive research, with a qualitative approach, when verifying cooperation in a credit cooperative. The research findings indicate that the Supervisory Board, in the credit union, is an organ that establishes a working relationship with the Board of Directors, providing an environment of transparency, of the cooperative's activities. This process presents the adoption of good management practices, contributing to the development of the membership and the community in which it operates. Thus, cooperation comes to be seen as a service delivery mechanism, in addition to presenting a work process with the power to generate a better distribution of income, in a democratic manner, with common economic and social objectives, distinct from other commercial societies. , who do not always seek to minimize the scarcity of economic opportunities, social deprivation, obstacles to freedom, which, in a way, accredit the world of cooperation for the achievement of a sustainable society

KeYwords: Competition. Cooperation. Sustainability. Complexity.

\section{INTRODUÇÃo}

A realidade brasileira e mundial apresenta um movimento complexo, um ambiente político, econômico, social e ambiental com rápidas e sucessivas mudanças, um acirramento da competição, onde a concorrência indica novos desafios para as configurações organizacionais, especialmente para as cooperativas, que possuem características especiais, que as diferenciam das empresas exclusivamente mercantis. Entre essas características cooperativas pode-se destacar, são sociedades de pessoas, não só de capital; cada associado representa um voto, já nas organizações mercantis o poder se baseia na quantidade de cotas/ações dos acionistas.

No entender de Pivoto (2015) a cooperativa é uma associação e uma empresa. Associação de pessoas, com interesses semelhantes, a empresa é a unidade econômica, criada pela associação, para atender as necessidades dos associados. Esse movimento, conta com um modelo de desenvolvimento em curso, que apresenta dificuldade em responder aos novos desafios impostos pela globalização.

A globalização busca uma homogeneização no território, ao estimular o espirito egoísta, individualista, concentrador da riqueza. Significa, que esse movimento gera mudanças na vida das pessoas, onde se estabelecem as relações entre indivíduos ou grupos, por um lado de insegurança, de competividade e de outro, gera um espaço 
onde ocorrem tanto as relações de cooperação.

Portanto, destes embates, entre competitividade e cooperação, surgem relações, mediante conversações sociais, resulta a projeção das expectativas das pessoas, entre outras, a da cooperação. Na acepção de Schneider e Hendges (2006), a cooperação não é caracterizado pela competição, pelo egoísmo ou pela obediência cega. $\mathrm{O}$ quadro de sócios não é orientado de forma mecânica, instrumental, robotizada, mas sim, consubstanciada pelos princípios democráticos, em um movimento que oportuniza o crescimento de homens e das mulheres, nos níveis: moral, social, cultural e intelectual.

No entanto, para Barbieri (1996, p. 12), “o desenvolvimento que significa ato de crescer, progredir, não deve ser entendido, necessariamente, como crescimento ilimitado, uma vez que, os ecossistemas possuem seus limites para fornecer a energia a esse crescimento". Assim, a busca do desenvolvimento, com princípios cooperativistas, será um desafio nas práticas cooperativas, pela alta competitividade presente na sociedade capitalista.

Assim, o desenvolvimento sustentável, para Sachs (1986), indica a necessidade de um planejamento, que contempla um modelo de desenvolvimento descentralizado e participativo. Essa dinâmica deverá contemplar a presença das organizações da economia cooperativa, da sociedade civil, com uma nova articulação entre Estado e as mais variadas organizações da sociedade.

Para Castilho (2011) o movimento cooperativo apresenta possibilidades em firmar suas raízes em empreendimentos locais, na sociedade em que está inserido, diferente das organizações transnacionais, mercantis, que trabalham em uma lógica contratual internacional. Assim, o cooperativismo pode ser considerado um mecanismo econômico e social, com capacidade de inclusão, de resgate da cidadania e, portanto, de desenvolvimento, na acepção de Annibelli (2008).

A busca do desenvolvimento em empreendimentos cooperativos, do quadro de sócios, da comunidade onde está inserido, necessita contar com princípios cooperativistas, o que não significa que em seu interior, não se reproduzem as relações de competição. Esse embate necessita contar com organizações cooperativista que estabelecem estratégias viáveis para o enfrentamento da concorrência, ao alimentar a crença na confiança, onde pode coexistir a cooperação e a competição na busca de um poder cooperativo. Cooperação entre o quadro social e a disputa de um espaço na sociedade, na conquista de mercados.

Portanto, para entender essa complexidade, entre o mundo da cooperação e da competição, o estudo aponta a necessidade de pesquisas, que permeiam não só referencial teórico, fundamentado na ciência, bem como, um olhar para as práticas 
cooperativas, mediante um caminhar metodológico que contempla uma análise da cooperação e competição, tendo presente o desenvolvimento sustentável, e, por fim, a conclusão.

\section{REFERENCIAL TEÓRICO}

As abordagens teóricas integram a produção científica, buscam estabelecer um diálogo, que consiste, em discussões feitas, por vários autores, sobre a temática, servindo como lente, como embasamento para os pesquisadores entenderem o cooperativismo e o desenvolvimento sustentável.

As cooperativas são organizações, formadas por pessoas, tendo como movimento inicial, 27 tecelões, que constituíram uma pequena cooperativa de consumo chamada "Sociedade dos Probos Pioneiros de Rochdale", em 1844 na Inglaterra. Desde os pioneiros de Rochdale, os princípios do cooperativismo, estão presentes, foram aperfeiçoados e são de fundamental importância, para o fortalecimento das práticas cooperativistas, no entender Pinho (2003), bem como necessitam de novos estudos, novas produções científicas.

As cooperativas, segundo o artigo $4^{\circ}$ da Lei Cooperativista 5.764/1971 "são sociedades de pessoas, com forma e natureza próprias, de natureza civil, não sujeitas à falência, constituídas para prestar serviços aos associados”. A legislação aponta que, à cooperativa cabe "o exercício da atividade econômica, de proveito comum, sem objetivo de lucro" (BRASIL, 1971).

Para Frantz (2006), o cooperativismo apresenta uma rica história, onde homens, que necessitam viver, buscam alternativas para sua sobrevivência. Pivoto (2015, p.42) "o negócio cooperativo conta com um conjunto de orientações que estabelecem a forma de relacionamento entre a cooperativa e cooperados [...] seguem as orientações dos Princípios Cooperativistas".

Meinen e Port (2016) corroboram ao afirmarem que o cooperativismo, se apresenta com legitimidade, como um movimento propulsor, da construção de uma sociedade mais equilibrada, inclusiva e sustentável. Esse processo oportuniza um ambiente favorável, para uma integração da cooperativa com a comunidade.

A possibilidade de integração com a comunidade, está presente nos sete ramos do cooperativismo (agropecuário, consumo, crédito, infraestrutura, saúde, trabalho, produção de bens e serviços e transporte) de acordo com os dados da (OCB, 2020), contribuindo no processo de organização dos associados, em um trabalho coletivo nos empreendimentos cooperativados. Alguns ambientes cooperativados necessitam seguir regras e normas de um órgão regulamentador, que é o caso das cooperativas de crédito, que são orientadas, como qualquer outra instituição 
financeira, pelas regras e normas impostas pelo Banco Central do Brasil (BACEN) e pelo Conselho Monetário Nacional (CMN), as Cooperativas de Saúde seguem as regras da Agência Nacional de Vigilância Sanitária (Anvisa), na Infraestrutura pela Agência Nacional de Energia Elétrica (ANEEL), o que não ocorre em cooperativas agropecuárias.

Se por um lado as cooperativas são sociedade que se organizam de acordo com as necessidades de seus cooperados, por outro lado necessitam seguir a legislação. Porém, os maiores desafios do cooperativismo, residem em trabalhar a cooperação e competição, que no entender de Brandenburger e Nalebuff (1996) permite indicar o termo "coopetição", uma combinação entre cooperação e competição, onde em alguns momentos se compete( na busca de mercados) e, em outros, se coopera (na cooperativa) mas ambos são indispensáveis e desejáveis em estratégia de empreendimentos cooperativos e que podem gerar uma inteligência coletiva, em seu quadro, para redimensionar a transformação social, uma busca de um novo processo de desenvolvimento sustentável.

Segundo a Organização das Cooperativas do Brasil (OCB, 2018), seria difícil encontrar um sistema mais eficaz do que o cooperativo para encorajar e estimular a participação ativa das populações, na realização de programas de desenvolvimento sustentável.

Portanto, o movimento em defesa da economia cooperativista, vive um período de transformações, o modelo de desenvolvimento em curso, apresenta dificuldades para responder, os desafios impostos pela globalização. Segundo Pinho (1965) combater o lucro e a concorrência, em graus selvagens, incontroláveis, responsáveis pelos males - as injustiças sociais - passa a ser um caminho essencial do cooperativismo para minimizar as crises econômicas e sociais.

Assim, para Frantz (1985) o movimento cooperativista, é uma organização, não de capitais e sim de pessoas, que buscam uma economia alicerçada nos componentes de sua associação, isto é, na perspectiva de sua racionalidade econômica, de uma estrutura empresarial, que responde pelo campo econômico e de uma estrutura do poder, na organização cooperativa, com um olhar especial para o desenvolvimento sustentável.

Para Bosselmann (2008) a sustentabilidade pressupõe prosperidade econômica (desenvolvimento econômico) e justiça social (desenvolvimento social) como valores conciliáveis e elementos determinantes para assegurar níveis satisfatórios de bem-estar, em perspectiva individual e coletiva, numa escala duradoura. Assim, o cooperativismo poderá ser um mecanismo, para promover prosperidade econômica de longo prazo e justiça social dentro dos limites da sustentabilidade social.

Nessa perspectiva, o cooperativismo e o desenvolvimento sustentável, estão 
vinculados em última análise, a um compromisso de longo prazo, de proteção da vida e das bases indispensáveis ao seu desenvolvimento, representadas na forma da redação exposta pelo artigo 225, $\$ 1^{\circ}$, inciso I, da Constituição Federal de $1988^{5}$.

Significa que a ordem jurídica brasileira, propõe o desenvolvimento sustentável, aproximando-o da proteção de um princípio de sustentabilidade. Assim, a experiência jurídica aponta um imperativo de proteção da durabilidade da vida, um Estado socioambiental, que se realiza por meio de instrumentos, princípios e objetivos de um direito de sustentabilidade (LEITE, 2011, p. 22-23).

Ademais, o desenvolvimento sustentável pode ser sintetizado e melhor definido

como um dever de proteger e de restaurar a integridade dos sistemas ecológicos terrestres, tal como se encontra expresso no texto da Carta Terra, sob a definição de um imperativo de integridade ecológica ${ }^{6}$ (UNESCO, 2000, p. 3).

Neste particular não se pode perder de vista o destaque feito pelo Relatório Brundtland - O Nosso Futuro Comum - (1991, p. 29) no sentido de que:

Há uma só Terra, mas não um só mundo. Todos nós dependemos de uma biosfera para conservarmos nossas vidas. Mesmo assim, cada comunidade, cada país luta pela sobrevivência e pela prosperidade quase sem levar em consideração o impacto que causa sobre os demais. Alguns consomem os recursos da Terra a um tal ritmo que provavelmente pouco sobrará para as gerações futuras. Outros, em número muito maior, consomem pouco demais e vivem na perspectiva da fome, da miséria, da doença e da morte prematura.

Portanto, essa nova dinâmica é pertinente, no entender de Acselrad, Mello e Bezerra (2009, p 135) ao destacarem que o capitalismo na atualidade "mostra-se [...] como um sistema que paralisa e captura os atores sociais no interior de 'alternativas infernais' - situações que não parecem deixar outra escolha além da resignação". Significa que as 'alternativas infernais' limitam o campo político e passam a se impor como norma, mecanismo de disciplinamento e controle. Esse modelo apresenta uma riqueza para um número reduzido de pessoas e a distribuição da pobreza para muitos. O império deste modelo gera uma relação autoritária e de exclusão (SOUZA, 2012, p. 213).

\footnotetext{
${ }^{5}$ Art. 225. Todos têm direito ao meio ambiente ecologicamente equilibrado, bem de uso comum do povo e essencial à sadia qualidade de vida, impondo-se ao poder público e à coletividade o dever de defendê-lo e preservá-lo para as presentes e futuras gerações.

${ }^{6}$ A carta da Terra define um princípio de integridade ecológica, um imperativo de concretização dos princípios definidos ao longo do texto. Define a integridade ecológica relacionando-a à necessidade de: "proteger e restaurar a integridade dos sistemas ecológicos terrestres com especial consideração à diversidade biológica e os processos naturais que sustentam a vida".
} 
Sachs (2009, p. 65-66) lembra que:

[...] o desenvolvimento é o processo histórico de apropriação universal pelos povos da totalidade dos direitos humanos, individuais e coletivos, negativos (liberdade contra) e positivos (liberdade a favor), significando três gerações de direitos: políticos, cívicos e civis; sociais, econômicos e culturais; e os direitos coletivos ao desenvolvimento, ao meio ambiente e à cidade [...]

Portanto, as fundamentações que consagram a sustentabilidade necessitam buscar novas estratégia, mais ágeis e eficientes para demonstrar a viabilidade do desenvolvimento equilibrado, seja na esfera ambiental como social, ultrapassando o discurso ambiental preservacionista e do fundamentalismo ecológico, meramente denunciatório (SOUZA, 2012, p. 217).

Para Faria, Souza e Silva, (2015) em um processo de governança na cooperativa, é indispensável participação democrática, para a conquista de uma mudança substancial no atual quadro de políticas públicas. O planejamento deve ser compreendido não apenas como orientado pelas necessidades da população, mas também, como conduzido por ela. A força da sociedade civil, como impulsionadora de um movimento político, uma força motriz, de um projeto de desenvolvimento sustentável, criando espaços para o movimento cooperativista, na buscar da sustentabilidade social.

As experiências do cooperativismo, permitem desenhar a conquista de uma certa autonomia do quadro associativo, uma inserção na comunidade, especialmente para enfrentar os problemas crucias de interesse coletivo. O movimento associativo, é, antes de tudo, uma busca consciente da sua existência. Assim, o desenvolvimento sustentável não é aquele que dá melhores resultados para o empreendimento cooperativado ou que harmoniza a produção capitalista, com garantida de um ambiente saudável, mas, aquele que busca a emancipação consciente dos associados.

Portanto, a consciência significa estar ciente de si mesmo, das próprias percepções, sentimentos e emoções. A consciência individual fragmentada impossibilita o advento da consciência coletiva, do bem comum, do compartilhamento das sobras no final do exercício, fruto da obra associativa, do empreendimento cooperativado.

O negócio cooperativo destaca Pivoto (2015, p. 42),

[...] conta com um conjunto de orientações que estabelecem a forma de relacionamento entre a cooperativa e os cooperados. Essas orientações são denominadas "Princípios Cooperativistas" e tornam-se diferentes de outros empreendimentos econômicos. Tais diferenças são encontradas na finalidade 
de cooperativa, na forma de propriedade e de controle e na forma como são distribuídas as sobras operacionais geradas.

Corroboram Ferreira e Arbage (2016) ao olharem para as cooperativas, identificando duas dimensões: uma econômica e uma social, ou seja, é uma organização que possui uma atividade econômica, porém necessita gerar benefícios, ou seja, melhorias para o seu quadro social. Isso caracteriza um desafio, que é manter o equilíbrio entre o lado empresa e o lado associação de pessoas.

A busca do equilíbrio, na dimensão do social e do econômico é o principal desafio do cooperativismo segundo Boesche e Mafioletti (2005), uma vez que, o ambiente de competição das cooperativas é o mesmo de todas as outras organizações. Por isso, as cooperativas precisam ser economicamente eficientes, para se manterem no mercado, mas sem deixar de lado a finalidade social, a busca por uma melhor qualidade de vida do quadro associativo, a conquista do desenvolvimento sustentável.

\section{Caminhos metodológicos da Pesquisa}

Os caminhos metodológicos contam com a abordagem "a que se fundamenta principalmente em análises qualitativas, caracterizando-se, em princípio, pela não utilização de instrumental estatístico na análise dos dados" (VIEIRA, 2004, p.17).

Denzin e Lincoln (2006) corroboram com o uso da pesquisa qualitativa, ao indicarem que esse processo trabalha com um conjunto de práticas, materiais para contribuir nas interpretações, que podem visibilizar estudos, na tentativa de entender o fenômeno a ser investigado. Já no entender de Munhoz (1989) e Cooper e Schindler (2003) indicam a pesquisa qualitativa que possibilita diagnosticar a temática, trabalhando-a de forma mais precisa, para que futuras pesquisas possam formular "leis" que regulam comportamentos sociais, em um ambiente de profundas contradições no modo de produção, que é o capitalista.

Assim, as contradições presentes na sociedade, no cooperativismo têm incitado trabalhadores e intelectuais a buscarem novas formas de produção, onde o ser humano passe a ser o centro da finalidade do processo produtivo. Essa oportunidade poderá credenciar o cooperativismo, enquanto movimento associativo, onde as sobras são distribuídas de acordo com a participação de cada associado. Essa realidade poderá ser explicada de "como e porque" de certos acontecimentos sociais estabelecem ligações operacionais, tornando-se um ambiente fértil para pesquisas qualitativas (YIN, 2005).

Portanto, nesta matriz de pesquisa, está presente a postura dos pesquisadores, que por mais de 20 anos, atuam em cooperativas, seja como trabalhadores, seja como pesquisadores, buscam contribuírem de forma consciente, para auxiliarem 
na compreensão do mundo cooperativo, do desenvolvimento sustentável e assim auxiliar na construção do conhecimento, para além dos muros da universidade e, efetivamente, somar com estudos, que possam indicar horizontes, na fundamentação teórica, com olhar crítico, para o mundo cooperativista, como possibilidade de conquistas no desenvolvimento sustentável.

Para além das fundamentações teóricas, a pesquisa conta com pesquisas realizada em cooperativa de crédito, que na atualidade ocupa um espaço estratégico no ranking financeiro, o que indica a necessidade de um "[...] conjunto de métodos ou caminhos que são percorridos na busca do conhecimento" (ANDRADE, 2006, p. 129). Neste olhar, um dos caminhos, pode ser o estudo de caso, que para Vergara (2013), consiste em uma pesquisa aplicada, de caráter qualitativo, para além, a pesquisa descritiva, interpretativa, para gerar dados e informações, a partir de objetivos definidos relacionados a um determinado problema (COLLIS e HUSSEY, 2005), que neste estudo objetiva produzir uma coexistência entre a cooperação e a competição, com interfaces entre o movimento cooperativista e a sustentabilidade.

\section{Análise e discussão dos aCHADOS NA PESQUiSA}

As investigações sobre a temática da cooperação e competição e suas interfaces com o desenvolvimento sustentável. Esse movimento permeiam a vida acadêmica, as organizações cooperativistas, as instâncias governamentais, porém necessitam de estudos, para entender as práticas sociais do fenômeno, para assim contribuir no processo de desenvolvimento da sociedade.

Para Bialoskorski Neto (2012), há necessidade de fazer adaptação, tanto com relação ao aporte teórico da cooperação, como na filosofia cooperativista, nas estruturas tradicionais de organização, no processo decisório. Já para Boisier (2000) existe uma complexidade no conceito de desenvolvimento e em sua natureza utópica, bem como nos diversos adjetivos atribuídos ao termo, tais como: territorial, regional, local, endógeno, de cima para baixo e de baixo para cima.

Ainda, para Boisier (2003), uma forma para diferenciar o termo "local" e "regional" em apenas dois pontos: a escala territorial e a escala funcional; entre crescimento e desenvolvimento. Assim, a ideia de desenvolvimento, parte do pressuposto de que o sistema produtivo local, presente no cooperativismo conta com investimentos concretizados, de um lado empresa cooperativa, de outro, a organização do quadro associativo.

Portanto, o movimento cooperativista, conta com práticas que necessitam de um olhar científico para verificar a sua operacionalidade, que ultrapassa a visão instrumental e tecnológica e que dialoga com as relações sociais complexas, como 
um espaço de poder, para conquistar mercados e por consequências benefícios para os associados.

Assim, a análise da organização política, que permeia ações efetivas nas cooperativas, práticas que contemplam alianças estratégicas, para ampliar a capacidade empresarial, a conquista de mercados (demanda) e das cadeias de produção (oferta). São iniciativas que devem contar com a capacidade de concertação existente, exigindo o comprometimento dos associados, de suas organizações: em nível estadual, da Organização das Cooperativas do Estado do Rio Grande do Sul; em nível nacional, da Organização das Cooperativas Brasileiras e em nível continental, da Aliança Cooperativa Internacional.

Entende-se que movimento cooperativista, internacional e nacional, poderá contribuir com as organizações cooperativistas locais, na busca responsável do desenvolvimento, para além dos aspectos econômicos, sociais e os ambientais, para Schmidheiny (1992) e Drucker (2000). Já para Sen (2003) o conceito de sustentabilidade, necessita conquistar uma melhor qualidade de vida, a eliminação da pobreza e da tirania, da escassez de oportunidades econômicas e das privações sociais, do abandono em que podem ser encontrados os serviços públicos, obstáculos à liberdade.

As análises de Albuquerque Llorens (2001) e Dowbor (2009) indicam a visão mais ampla, de conjunto, ao buscar a associação das áreas: econômica, social e ambiental, em direção ao desenvolvimento que deverá contar com as políticas públicas, com investimentos estratégicos do Estado, com possibilidades de contribui no processo de desenvolvimento do movimento cooperativista.

As reflexões de Junqueira (2000) e Buarque (2006), indicam que o desenvolvimento regional pode tornar-se sustentável, ao implementar as potencialidades locais, entre elas a presença das cooperativas. Esse processo necessita contar com o campo social, enquanto espaço de buscar da viabilidade e da competitividade da economia local/regional. Essa caminhada deverá contar com a conservação dos recursos naturais locais, que encontram eco no sétimo princípio do cooperativismo: cooperativas trabalham para o desenvolvimento sustentado das suas comunidades.

Portanto, o desenvolvimento local/regional pode conquistar a promoção da autonomia das comunidades locais, de forma especial com a presença das cooperativas, enquanto agência do desenvolvimento. No entanto, importa saber, não se trata de uma autonomia política com características de movimentos de tipo nacionalista (isolamento) ou autárquico (centralismo), mas sim, de preservar uma identidade local, que concilia com estruturas políticas, institucionais e culturais para a conquista do desenvolvimento sustentável. 
Sampaio (2004) aponta novos critérios de racionalidade social: Participação, onde todos que integram o projeto de desenvolvimento devem participar do seu processo de planejamento, incorporando as três esferas de poder: Estado, Mercado e Sociedade Civil. O planejamento e a gestão do desenvolvimento devem contemplar uma metodologia sistêmica e complexa, ou seja, não setorial, bem como a potencialização dos saberes locais, as tecnologias apropriadas, externalizando a dimensão tácita do conhecimento.

Nas investigações do processo de planejamento, o movimento cooperativista pode ser visto como uma esfera de poder, um caminho para o desenvolvimento local, que poderá minimizar a pobreza e a tirania capitalista, a escassez de oportunidades econômicas e as privações sociais, a efetivação de uma sociedade mais justa e igualitária, reflexões presentes em Pinho (1977). Ainda, o autor reforça que o cooperativismo poderá auxiliar no combate das injustiças sociais. $\mathrm{O}$ cooperativismo é um sistema econômico e social utilizado no mundo inteiro, que tem na cooperação a base sobre as quais se constroem as atividades econômicas (SEBRAE, 2003).

Assim, as análises do campo político apontam a presença dos associados na estrutura do poder no movimento associativo, nas dinâmicas econômicas, empresariais. Para Figueiredo (2009) o empreendimento cooperativo é gerido democraticamente, por membros comprometidos e conscientes de seus direitos e deveres, tendo como pilares os princípios do cooperativismo: Adesão voluntária e livre; Controle democrático pelos sócios; Participação econômica dos sócios; Autonomia e independência; Educação, treinamento e informação; Cooperação entre cooperativas e Preocupação com a comunidade. Complementa Thesing (2015) que o movimento cooperativista não aceita a discriminação social, racial, politica, religiosa e de sexo, indicando uma preocupação com o desenvolvimento sustentável das comunidades.

Nas investigações de Silva (2018) as cooperativas buscam a prosperidade das comunidades onde estão inseridas, por um modelo capaz de unir pessoas e gerar o desenvolvimento econômico e social. Significa, que as cooperativas podem buscar uma melhor qualidade de vida. Para Vasconcelos et al. (2002), o desenvolvimento é um processo associado a melhoria das condições de vida da população ou da qualidade de vida das pessoas.

As pesquisas em Hirschman (1961, p. 19) apontam que o desenvolvimento "não depende somente de encontrar ótima confluência de certos recursos e fatores de produção, quanto de provocar e mobilizar com propósito desenvolvimentista, os recursos e as aptidões que se acham ocultos, dispersos ou mal-empregados". Sen (1999) registra em suas análises, a presença marcante das pessoas, dando significado 
nos discursos em torno do desenvolvimento, onde o movimento cooperativista, apresenta sua centralidade, por ser constituídos por pessoas e não de capitais.

Assim, a pesquisa semiestruturada, aplicada aos Conselheiros Fiscais, da Cooperativa de Crédito, apontam a importância dos associados, mesmo sendo uma cooperativa que opera com capital financeiro. Os conselheiros indicaram na pesquisa que buscam novos conhecimentos, novas ferramentas nos processos de fiscalização, melhorias nos processos decisórios e aprimoramentos dos modelos de prestação de conta e de indicadores de desempenho, o tratamento adequado e justo aos associados, a responsabilidade perante a sustentabilidade da cooperativa, focando à sua longevidade, acrescendo considerações de ordem social e ambiental.

A pesquisa identificou desafios a serem superados, entre eles se destaca a escolha dos candidatos a ocuparem o cargo de Conselheiro Fiscal, onde nem sempre é observado as Boas Práticas da Governança, que prevê que "as organizações devem estimular o debate entre todos os sócios quanto à composição do órgão buscando garantir que ele tenha a diversidade desejável de experiências profissionais pertinentes às suas funções e ao campo de atuação da organização" (IBGC 2015a, p83).

A Lei 5.764 aponta de como são realizadas as eleições e a renovação dos membros do Conselho Fiscal, bem como deve ser constituído de 3 (três) membros efetivos e 3 (três) suplentes, sendo permitida apenas a reeleição de 1/3 (um terço) dos seus componentes. Essa observação foi constatada nas entrevistas na cooperativa de crédito, como também apontaram que a cooperativa é regulamentada pelo BACEN.

Portanto, as cooperativas de crédito, especificamente, podem ser entendidas como portas estratégicas para adentrar no processo de desenvolvimento da economia local. O estudo contemplou uma instituição financeira cooperativada, que busca a implantação do modelo de governança a partir da identificação das boas práticas que exercem maior impacto no desempenho do empreendimento e na comunidade.

Assim, o cooperativismo pode acessar as práticas do desenvolvimento sustentável, ao contar com a participação do quadro associativo, da comunidade çom possibilidades na conquista de qualidade de vida a partir de ações comunitárias (ÁVILA, 2000).

Os estudos de Alves (2003), permitem uma análise que contempla a presença da comunidade, dos associados da cooperativa, que reforça a possibilidade do desenvolvimento econômico e social em uma região, de estados ou país, a partir de oportunidades de trabalho, na geração de renda, no fortalecimento das instituições democráticas, com distribuição das sobras do balanço da cooperativa. 
A multiplicação das cooperativas, busca a sustentabilidade dos pequenos empreendimentos, fortalecendo o cooperativismo ao longo dos anos, especialmente com destaque no Rio Grande do Sul. Significa que, o cooperativismo passa a ser uma prática reconhecida como um sistema que integra, micros, pequenos, médios e grandes produtores, colocando-os no mesmo patamar de igualdade, a partir dos princípios cooperativistas (SCHNEIDER, 2016).

Assim, as investigações científicas permitem afirmar que o movimento cooperativista poderá conquistar, um espaço público, não estatal, para auxiliar no desenvolvimento sustentável. Apresenta uma atitude ética, uma percepção de conjunto, onde "ser humano é viver e atuar em conjunto" no dizer de Thesing (2015, p.97). Ainda, o autor sustenta que essa força gregária, o esforço coletivo, possibilita a marca de humano, onde a arte de cooperar possa a somar em cada homem e em cada mulher uma atitude de desprendimento, vontade de partilha, que pode ser conquistado pela aprendizagem, na conquita por melhores dias, para o quadro associativo, em todos os lugares e processos concretos da vida nos quais o ser humano realiza sua natureza social. Já apontava Frantz (2002, p.61), “ainda por mais distante que o percebamos, vemos no cooperativismo uma possibilidade de poder contribuir com uma nova oportunidade à vida futura em nosso planeta".

\section{CONSIDERAÇões FinaIS}

Ao realizar a pesquisa do fenômeno, identificado como movimento cooperativista, enquanto espaço socioeconômico, com a presença de milhares de associados, que estabelece interfaces, pelas suas entre as ações com a sustentabilidade, onde coexistem a cooperação e a competição. Assim, tem-se presente os benefícios providos pelo processo de cooperação, entre os associados, com melhorias nos processos decisórios e nos aprimoramentos dos modelos de prestação de conta, com a operacionalização de indicadores de desempenho, com a busca da sustentabilidade, em um mercado de alta competição, o que desafia a busca de novos mercados para os produtos, serviços.

Assim, ao verificar a cooperativa de crédito, os conselheiros apresentaram a importância do ramo, apontando os resultados da Organização das Cooperativas do Brasil, que em seus relatórios indicam a presença de 909 Cooperativas de Crédito, que atendem 9.840.977 associados com 67.267 funcionários. Estes números, demonstram que a perenidade das cooperativas, sua importância na sociedade.

A pesquisa identificou que o Conselho Fiscal tem um destacado papel, na relação de trabalho com o Conselho Administração, na transparência das atividades da cooperativa de crédito. Esse processo apresenta a adoção de boas práticas de gestão, 
contribuindo com o desenvolvimento do quadro associativo e com a comunidade onde está inserido.

Os bons resultados permitem apontar a perenidade da cooperativa, bem como com possibilidade de acessar novas conquistas, entre elas, uma melhor qualidade de vida, que desafia o diálogo entre os conceitos e interfaces das várias áreas do saber, para realizar uma análise das complexidades contemporâneas, do movimento cooperativista e o desenvolvimento sustentável. Por esta razão, faz-se necessário trilhar entendimentos quantitativos, de melhorias nas condições da vida humana

É conveniente entender que a qualidade de vida não se confunde com padrão de vida, que é uma medida que quantifica a qualidade e quantidade de bens e serviços disponíveis. Qualidade de vida dialoga com o desenvolvimento sustentável. Um processo que contempla as condições materiais existentes; os distintos graus de consciência política entre os diversos sujeitos, grupos sociais e comunidades; tantos os conhecimentos específicos sobre determinados assuntos envolvendo a questão da sustentabilidade (econômicos, sociais, culturais, técnico-tecnológicos, ecológicos, territoriais, biológicos, legais, pedagógicos, da saúde, entre tantos outros), como a condição de trabalhar estes conhecimentos na relação entre a cooperação e a competição, presentes na cooperativa e na sociedade.

O movimento cooperativista pode ser entendido como porta estratégica de entrada no processo de desenvolvimento sustentável, ao contar com a dimensão associativa, um processo de reconstrução das relações humanas, a realização do bem comum, alicerçado no trabalho, para a conquista de um ambiente coletivo, organizado pelas economias individuais, dos associados, para consolidar os empreendimentos cooperativados. De outro lado, enfrenta a competição ao disputar novos mercados na sociedade, que é alimentada pela competição, pela individualidade, pela concentração da renda e da riqueza.

Assim, ao interpretar as práticas de cooperação e o processo de desenvolvimento sustentável, é possível registrar que as práticas não se apresentam como práticas neutras, livres de interesses e intenções e sim "politizam-se" em atividades de poder. Um poder que o quadro associativo pode conquistar em uma sociedade altamente competitiva e concentradora da riqueza, ao valorizar o trabalho, nos processos produtivo, comercial, industrial, serviços, uma vez que, a cooperação pode ser um mecanismo de organização e estruração do trabalho em empreendimentos empresariais ou sociais.

Por fim, na organização de sociedades sustentáveis, as contribuições do movimento cooperativista, que trabalham para manter a longevidade do cultivo da terra, na estabilidade econômica e produtiva, no acesso à transição energética, em 
diversos setores (saúde, comunicações, turismo) no abastecimento sustentável de produtos, na conquista de moradias seguras e acessíveis. A cooperação desenvolve sociedades sustentáveis, com democracia, igualdade e justiça social. As sociedades não podem continuar desperdiçando recursos e excluindo pessoas. Significa melhorar o presente para preservar as próximas gerações. Entretanto, vislumbrase a oportunidade de novos estudos que possam contribuir na perenidade das cooperativas, ao realizar uma pesquisa que possam verificar o mundo cooperativo em sociedades de alta competitividade, de concentração de renda, de exclusão social.

\section{REFERÊNCIAS}

ACI-Aliança Cooperativa Internacional. Informações estatísticas sobre o movimento Cooperativo. Disponível em: http://www.ica.coop/coop/statistics.html. Acessado em setembro, de 2019.

ANDRADE, M. M. de. Introdução à Metodologia do Trabalho Científico. São Paulo: Atlas,2006.

ACSELRAD, H.; MELlO, C. C. de A.; BEZERRA, G. das N. O que é justiça ambiental. Rio de Janeiro: Garamond, 2009.

ANUÁRIO DO COOPERATIVISMO, 2019. Disponível em: http://www. paranacooperativo.coop.br/ppc/images/Comunicacao/2019/noticias/07/04/ publicacao/publicacao clique aqui 04 07. Acessado em setembro de 2019.

ALBUQUEQUE LLORENS, F. Desenvolvimento econômico local: caminhos e desafios para a construção de uma nova agenda política. Tradução de Antônio Rubens Pompeu Braga. Rio de Janeiro: BNDES, 2001.

ANNIBELLI, M. B. A Ordem Econômica Brasileira e o Cooperativismo. Revista Eletrônica do CEJUR, Vol. 1, No. 3, 2008.

ALVES, A. G. M. P. As cooperativas agropecuárias e o brde: histórico, situação atual e perspectivas. Banco Regional de Desenvolvimento do Extremo Sul, Porto Alegre, 2003.

ÁVILA, V. F. de. Pressupostos para Formação Educacional em Desenvolvimento 
Local. Interações: Revista Internacional de Desenvolvimento Local. Vol.1, n.1, p. 63-76, set. 2000. Campo Grande: UCDB, 2000.

BARBIERI, J.C. Desenvolvimento e Meio Ambiente: As Estratégias de Mudança da Agenda 21. 1. Ed. Petrópolis, Rio de Janeiro: Vozes, 1996.

BIALOSKORSKI NETO, S.; BALIEIRO, C. F. Capital social e cooperativas na agricultura do estado de São Paulo: um ensaio analítico. Texto para Discussão Comissão de Pesquisa e Publicações da FEA-RP/USP. Ribeirão Preto, 2000.

BIALOSKORSKI NETO, S.; SOUZA, J. V. P., GARCIA, L. F. Cooperativas de leite no Brasil: estratégias e tendências. In: Estratégias para o leite no Brasil. CONSOLI, M. A.; NEVES, M. F. (Orgs). São Paulo, Atlas, 2004.

BIALOSKORSKI-NETO, S. Economia e gestão de organizações cooperativas. São Paulo: Atlas, 2012.

BOISIER, S. Desarollo (local): de que estamos hablando? In: BECKER, D.: BANDEIRA, P. S. F. Desenvolvimento local e regional: determinantes e desafios contemporâneos. Santa Cruz do Sul: UNISC, 2000.

BOSSELMANN, K. The principle of sustainability: transforming Law and governance. Aldershot: Ashgate, 2008.

BOESCHE, L.; MAFIOLETTI, R. L. Evolução e indicadores do cooperativismo brasileiro paranaense. Curitiba: Sistema Ocepar, 2005.

BUARQUE, S. C. Construindo o desenvolvimento local sustentável: metodologia de planejamento. 3. Ed. Rio de Janeiro: Garamond, 2006.

BRANDENBURGER, A; NALEBUFF, B. Co-opetição. São Paulo: Rocco, 1996.

BRASIL. Lei n.o 5.764, de 16 de dezembro de 1971. Define a política nacional de cooperativismo, institui o regime jurídico das sociedades cooperativas e dá outras providências. Disponível em: http://www.planalto.gov.br/ccivil_03/leis/L5764.htm Acesso em: maio de 2020.

CARTA DA TERRA - Organização das Nações Unidas, 2002. 
CASTILHO, R. Direitos Humanos. São Paulo, Saraiva, 2011.

COMISSÃO MUNDIAL SOBRE MEIO AMBIENTE E DESENVOLVIMENTO. Nosso Futuro Comum. Rio de Janeiro: Editora da Fundação Getúlio Vargas, 1991.

COOPER, D. R., SCHINDLER, P. S. Métodos de pesquisa em Administração. [Trad. ] Luciana de Oliveira da Rocha. Porto Alegre: Bookman, 2003.

COLLINS, J., HUSSEY, R. Pesquisa em Administração. São Paulo: Bookman, 2005.

DENZIN, N. K.; LINCOLN, Y. S. Introdução: a disciplina e a prática da pesquisa qualitativa. In: DENZIN, N. K.; LINCOLN, Y. S. (Orgs.) O planejamento da pesquisa qualitativa: teorias e abordagens. 2. ed. Porto Alegre: Artmed, 2006.

DOWBOR, L. Da globalização ao poder local: a nova hierarquia dos espaços. Artigos Online. São Paulo, 2009. Disponível em: http://dowbor.org/5espaco.asp. Acessado, maio, 2020.

DRUCKER, P. F. Liderança para o século XXI. São Paulo: Futura, 2000.

FARIA, J. H. de; NEVES, R. Por uma teoria crítica da sustentabilidade. In. SANTOS, L. (org.). Sustentabilidade: anais de textos selecionados do $5^{\circ}$ Seminário sobre Sustentabilidade. Curitiba: Juruá, 2011.

FARIA, S. R.; SOUZA, A.; SILVA, W. Governança Corporativa em Cooperativas Agropecuárias: um modelo de classificação com aplicação da ferramenta Walk. Race, Unoesc, v. 14, n. 1, p. 313-332, jan. /abr. 2015.

FERREIRA, G. M. V.; ARBAGE, A. P. Governança e sua relação com a fidelidade em cooperativa. Porto Alegre: Ed. Buqui, 2016.

FIGUEIREDO, M. H. J. S. Enfermagem de família: um contexto do cuidar. (Tese de Doutoramento em Ciências de Enfermagem). Porto. Instituto de Ciências Biomédicas Abel Salazar, 2009.

FRANTZ, W. O Cooperativismo e a Prática Cooperativa. In: Perspectiva Econômica, Ano XIX, n51, Série Cooperativismo n 16, São Leopoldo: UNISINOS, 1985. 
FRANTZ, W. Cooperativismo: perspectivas. Um lugar de reencontro com a vida. Ijuí: UNIJUÍ, 2002. (Cadernos Unijuí).

FRANTZ, W. Razões do cooperativismo moderno. O Interior, Porto Alegre, v. 32, n. 963, mar. 2006.

HIRSCHMAN, A. O. Estratégia do desenvolvimento econômico. Rio de Janeiro: Fundo de Cultura, 1961.

IBGC. Guia das melhores práticas de governança para cooperativas. 2015b. São Paulo: IBGC. Disponível em: http://www.ibgc.org.br/index.php/ publicacoes/guias/ guiacoop_web.pdf Acessado março 2020.

JUNQUEIRA, S. Intersetorialidade, transetorialidade e redes sociais na saúde. Rio de Janeiro: FGV, Revista de Administração Pública-RAP, 2000.

LEITE, J. R. M. Dano ambiental: do indivíduo ao coletivo extrapatrimonial. São Paulo: Revista dos Tribunais, 2011.

MEINEN, Ê; PORT, M. Cooperativismo financeiro, percurso histórico, perspectivas e desafios: De cooperativa de crédito a principal instituição financeira do associado. Brasília: CONFEBRAS,2016.

MUNHOZ, D. G. Economia Aplicada: Técnicas de Pesquisa e Análise Econômica. Brasília: Editora UNB, 1989.

OCB - Organização das Cooperativas Brasileiras. O que é Cooperativismo. Sistema OCB, 2018. Disponível em: https://www.ocb.org.br/o-que-e-cooperativismo. Acessado em março de 2020.

OCERGS/SESCOOP/RS. Sistema. (2018). Disponível em: http://www.sescooprs. coop.br/ Acesso em setembro/2019.

PINHO, D. B. O Cooperativismo no Brasil desenvolvido e no "Brasil Subdesenvolvido”. São Paulo: USP, 1965.

PINHO, D. B. O cooperativismo no Brasil: da vertente pioneira à vertente solidária. São Paulo: Saraiva, 2003. 
PINHO, D. B Economia e cooperativismo. São Paulo: Saraiva,1977.

PIVOTO, D. Governança cooperativa: os problemas dos direitos de propriedades difusos em cooperativas agropecuárias. 1. ed. Porto Alegre: Buqui, 2015.

SACHS, I. Desenvolvimento sustentável, Bio-Industrialização descentralizada e novas configurações rural-urbanas. Os casos da Índia e do Brasil. In: VIEIRA, P. F.

WEBER, J. (Org.). Gestão de recursos naturais renováveis e desenvolvimento: novos desafios para a pesquisa ambiental. 3. Ed.- São Paulo, Cortez, 2002.

SACHS, I. Caminhos para o desenvolvimento sustentável. Rio de Janeiro: Garamond, 2009.

SACHS, I. Ecodesenvolvimento: crescer sem destruir. São Paulo: Vértice, 1986.

SAMPAIO, J. R. e GOULART, I. B. Qualidade de Vida no Trabalho: Uma análise da Experiência de Empresas Brasileiras. Em SAMPAIO, J. dos R. (Org.) Qualidade de vida no Trabalho e Psicologia Social. 2a . ed. São Paulo: Casa do Psicólogo, 2004.

SEN, A. Desenvolvimento como liberdade. São Paulo: Companhia das Letras, 1999.

SEN, A. Por qué la equidade en salud? Pan American Journal of Public Health, 2003.

SILVA, P. R. da. Organização, Sistemas e Métodos. Maringá-Pr.: UniCesumar, 2018.

SOUZA, J. F. V. de; CANDIOTO, R. A. Qualidade de vida e meio ambiente: um debate para mudanças socioeconômicas e políticas no Brasil. Cadernos de Direito, Piracicaba, v. 13(24): 9-34, jan.-jun. 2013. Disponível em: https://www.metodista. br/revistas/revistasunimep/index.php/direito/article/view/1832/1143 Acesso em maio 2020.

SOUZA, J. F. V. de. Água: fator de desenvolvimento e limitador de empreendimento. São Paulo: Modelo, 2012.

SCHNEIDER, J. O.; HENDGES, M. Educação e Capacitação Cooperativa: sua importância e aplicação. ESAC Economia Solidária e Ação Cooperativa: Unisinos, 2006. 
SCHNEIDER, J. O., BAVARESCO, R. Tendências do Cooperativismo Agropecuário no Rio Grande do Sul. Editora Unisinos, São Leopoldo, 2016.

SCHMIDHEINY, S. Mudando o rumo: uma perspectiva empresarial global sobre desenvolvimento e meio ambiente. Rio de Janeiro: Ed. FGV, 1992.

THESING. N. J. Por um Mundo Melhor: Cooperação e Desenvolvimento. Sescoop/ RS. Porto Alegre. 2015.

UNESCO. The Earth Charter. 2000. Disponível em http://www.unesco.org/ pv_obj_cache/pv_obj_id_286DCA912BADC463E4DB347EE93824AF86830000/ filename/02_earthcharter.pdf. Acesso em março de 2020.

VASCONCELLOS, M. Pensamento Sistêmico: O Novo paradigma da Ciência. São Paulo: Papirus, 2002.

VERGARA, S. C. Projetos e relatórios de pesquisa em administração. São Paulo: Atlas, 2013.

VIEIRA, M. Por uma boa pesquisa (qualitativa) em administração. In: VIEIRA, M.; ZOUAIN, D. Pesquisa qualitativa em administração. Rio de Janeiro: FGV Editora. 2004.

YIN, R. K. Estudo de caso: planejamento e métodos. Porto Alegre: Bookman, 2005. 